\title{
Insulin-Like Growth Factor-1 and Anti-Vascular Endothelial Growth Factor in Retinopathy of Prematurity: Has the Time Come?
}

\author{
Andreas Stahl ${ }^{a}$ Ann Hellstrom ${ }^{b}$ Lois E.H. Smith ${ }^{c}$ \\ a Eye Center, University of Freiburg, Freiburg, Germany; ${ }^{b}$ Department of Ophthalmology, Institute of Neuroscience \\ and Physiology, The Sahlgrenska Academy, University of Gothenburg, Gothenburg, Sweden; ${ }^{\circ}$ Department of \\ Ophthalmology, Boston Children's Hospital, Harvard Medical School, Boston, Mass., USA
}

\section{Key Words}

Insulin-like growth factor 1 - Preterm birth · Retinopathy of prematurity · Vascular endothelial growth factor

\begin{abstract}
Treatment of retinopathy of prematurity (ROP) is currently evolving. Novel therapeutic options are emerging that have the potential to complement existing therapies and improve treatment outcomes. However, any new therapeutic option must be thoroughly evaluated before existing (and successful) treatment paradigms can be amended. This is particularly so when switching from locally effective therapies like photoablative laser therapy to systemic pharmacological treatments, which may have hitherto unknown widespread side effects. This review compiles the current knowledge of where and when the two most advanced pharmacological treatment options for ROP, insulin-like growth factor-1 supplementation and anti-vascular endothelial growth factor treatment, may have their place in future therapy regimens for ROP. The requirement for clinical studies is emphasized: these are needed to address safety considerations before any of these interventions can achieve the status of standard clinical care in the very vulnerable population of ROP infants.
\end{abstract}

(c) 2014 S. Karger AG, Basel

\section{KARGER}

(c) 2014 S. Karger AG, Basel

$1661-7800 / 14 / 1063-0254 \$ 39.50 / 0$

E-Mail karger@karger.com

www.karger.com/neo

\section{Introduction}

The term 'retinopathy of prematurity' (ROP) was first coined in the late 1940s. ROP replaced the earlier term 'retrolental fibroplasia', which described a complete retinal detachment visible as a fibrotic mass directly behind the lens. Today, ROP is divided into 5 stages. Stage 5 is a completely detached retina seen in retrolental fibroplasia. Due to advances in neonatal intensive care, rigorous ophthalmologic screening and adherence to treatment guidelines, stage $5 \mathrm{ROP}$ has become increasingly rare, as is stage 4 ROP with a partially detached retina. The most common proliferative ROP stages seen in developed countries today are stage 1 (demarcation line between vascularized and nonvascularized retina), stage 2 (prominent demarcation ridge between vascularized and nonvascularized retina) and stage 3 (demarcation ridge with extraretinal proliferations).

The reason for less late-stage retinal detachment is twofold. Improvements in the practices in neonatal intensive care units, such as oxygen control, reduce disease burden, as does ablation treatment. Most infants with ROP are identified early by ophthalmologic screening to initiate treatment in time to avoid progression to stage 4 or 5 ROP. In most countries, treatment criteria for ROP 
Fig. 1. Retinal vessels (red in the online version) grow in a centrifugal pattern from the optic nerve head towards the periphery of the retina, the ora serrata. In the mouse retina, retinal vascular growth occurs postnatally between postnatal days (P) 1 and 8 under normoxic $(\mathrm{N})$ conditions (referred to as P1N-P8N). In normal human development, retinal vascularization occurs in utero and the retina is fully vascularized at term. However, when development is disrupted by preterm birth, retinal vascular development can be severely suppressed or developed vessels can regress leading to ROP (reprinted with permission from ref. 3; copyright holder: Association for Research in Vision and Ophthalmology).

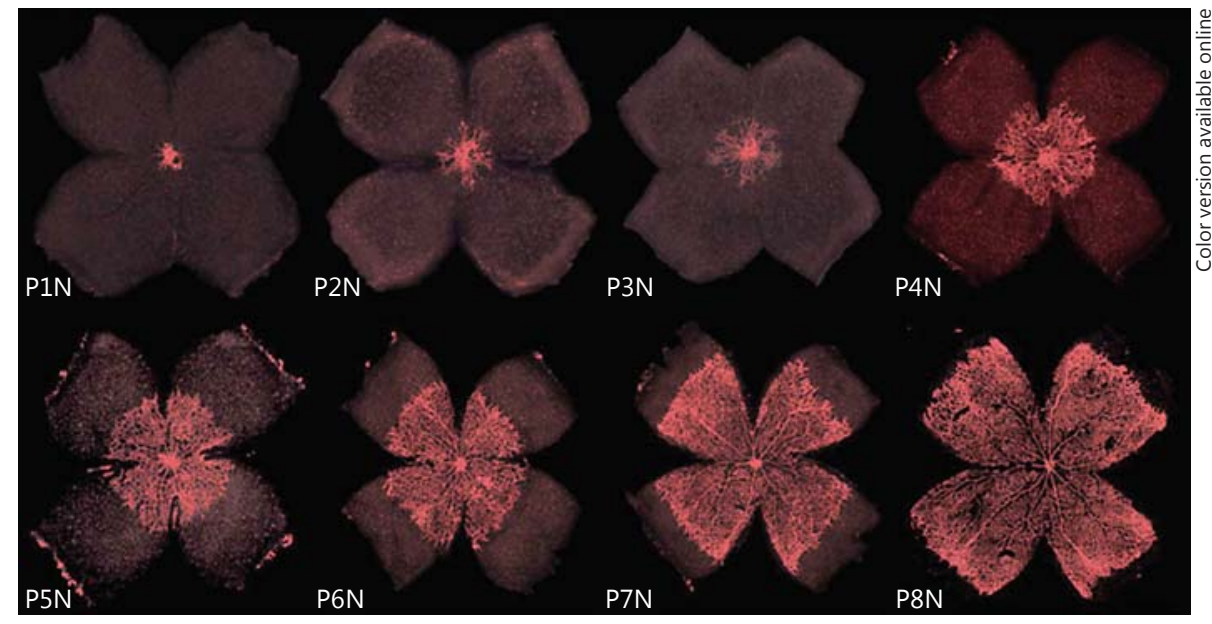

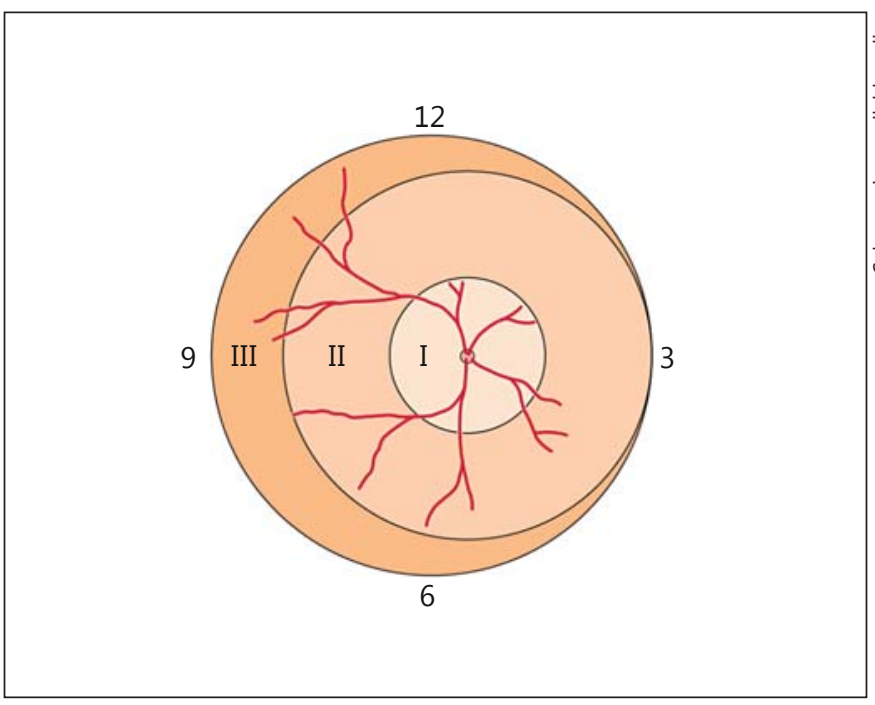

Fig. 2. Retinal zones used for grading ROP. Zone I describes a circle around the optic nerve head with a radius of twice the distance from optic nerve head to fovea. Zone II is a circle around the optic nerve head reaching the nasal periphery (at the 3 o'clock position in the image). Zone III is the remaining temporal crescent-shaped retina (reproduced with permission from ref. 6).

are adopted from the ETROP (Early Treatment for Retinopathy of Prematurity) study [1]. A treatment decision is based on ROP stage as well as on the tortuosity and dilation of retinal vessels and the zone of the affected retina. Physiologically, the eye is vascularized from the optic nerve with radial progression to the periphery [2]. Figure 1 demonstrates this centrifugal pattern of retinal vessel growth in the mouse retina.

IGF-1 and Anti-VEGF in ROP: Has the Time Come?
The earlier that normal retinal vascular development is disrupted by preterm birth, the greater the area of unvascularized retina. This avascular tissue is typically quiescent for the first weeks after birth while further retinal vessel growth is stalled. Later, [typically after 30-32 weeks of postmenstrual age (PMA)], as retinal photoreceptors mature and become metabolically active, the avascular retina becomes hypoxic and secretes hypoxia-regulated angiogenic growth factors like the vascular endothelial growth factor (VEGF) $[4,5]$. The greater the avascular area present, the higher the levels of VEGF that induce pathological vascular growth, i.e. vessels growing into the vitreous. To account for variable areas of avascular retina and the associated differences in angiogenic growth factor production, ROP is divided into three zones. Zone I refers to the vascularized retina that lies within a circle around the optic nerve head $(\mathrm{ONH})$ with a radius of twice the distance from $\mathrm{ONH}$ to fovea. Zone II is the vascularized retina within a circle around the $\mathrm{ONH}$ with the nasal curvature reaching the ora serrata (i.e. the nasal peripheral edge of the retina). Zone III is the remaining crescent-shaped area in the temporal part of the retina that remains outside zone II. Figure 2 summarizes the zones used for ROP grading.

Following ETROP criteria, all stages of ROP require treatment when the border between vascularized and unvascularized retina lies in zone I and 'plus disease' is present. 'Plus disease' refers to the dilation and tortuosity of retinal vessels and is an important indicator of disease activity. Vessel tortuosity in two or more clock hours at the posterior pole of the eye is generally accepted as sufficient to add the suffix 'plus' to an ROP stage, indicating high disease activity. Unlike zone I, zone II ROP only re- 
quires treatment when stages 2 plus or 3 plus are present. Zone III ROP rarely requires treatment; observation is usually sufficient until full retinal vascularization is documented.

It should be noted that not all national guidelines fully follow the ETROP criteria. For example the current German guidelines for treating ROP do not include ROP stage 2 plus in zone II, because many of these infants may never develop a proliferative ridge [7]. The German guidelines recommend tight ophthalmologic follow-up for stage 2 plus in zone II and treatment only when vasoproliferation appears on the ridge (i.e. when progression to stage 3 plus is noted over several clock hours of the retinal circumference in zone II).

\section{ROP Treatment: Cryo, Laser and Anti-VEGF Therapy}

Published in 1990, the CRYO-ROP study laid the foundation for ROP treatment $[8,9]$. The main finding was that infants treated with cryoablation of the avascular retina had fewer unfavorable structural outcomes compared to nontreated infants. In the 1990s, laser photocoagulation of the avascular retina was introduced as a treatment alternative to cryotherapy [10-12] and, today, has replaced cryotherapy in most countries [13]. Both cryo and laser therapy follow the same principle: avascular retina is destroyed in order to decrease the production of pro-angiogenic growth factors from hypoxic retinal cells. The treatment is safe and, when performed properly, in most cases stops disease progression before stage 4 or 5 ROP develops. For those cases in which laser treatment is insufficient or initiated too late and a retinal detachment has already occurred (or in cases where ROP proceeds despite treatment), retinal surgery to reattach the detached retina is warranted. However, treatment results for late stages of ROP are often disappointing [14, 15]. The goal is to identify and treat infants before stage 4 or 5 ROP develops. The downside of laser therapy, however, is that potentially viable retinal tissue is replaced with functionless scar tissue.

For the last several years, anti-VEGF treatment has been used as an off-label alternative to laser photocoagulation for ROP. The BEAT-ROP (Bevacizumab Eliminates the Angiogenic Threat of ROP) results published in 2011 were the first data from a multicenter randomized trial on anti-VEGF treatment in ROP [16]. The BEATROP study compared the effects of bevacizumab, an antiVEGF antibody, to the effects of conventional laser therapy. Recurrence of active ROP was the primary outcome.
There are several limitations to this study, one being the relatively short follow-up window precluding complete evaluation of systemic and ophthalmologic complications. Mean age for ROP treatment was about 34-36 weeks of PMA; the follow-up period was 20 weeks after treatment or up to 54 weeks of PMA. The BEAT-ROP study noted more ROP recurrences in the laser-treated group compared to the bevacizumab-treated group only in zone I ROP. ROP recurrence was similar for both therapies in infants with zone II ROP. Furthermore, the rate of ROP recurrences in the laser group was high compared to other studies. In addition, other reports note that ROP recurrences after bevacizumab treatment may occur much later than after laser therapy, therefore potentially occurring outside the observational window of up to 54 weeks of PMA in the BEAT-ROP study $[17,18]$.

Despite these caveats, the BEAT-ROP results raised some important points: (i) bevacizumab is effective in halting neovascular disease progression in ROP in most cases; (ii) unlike laser therapy, the avascular retinal areas are not destroyed but may become (partially) vascularized over time. Whether the vessels and underlying neural retina is normal is unknown. The BEAT-ROP results have thus introduced anti-VEGF treatment as a potential treatment option for ROP.

Nevertheless, some important questions remain. For example, there are currently only limited long-term data on visual function following anti-VEGF treatment in ROP. With VEGF being an important growth factor, not only for blood vessels but also for neuronal cells of the retina, it is essential to gather more data on long-term functional outcomes in the retina as well as in other organs [19]. The available data to date suggest that visual function is not significantly impaired compared to lasertreated eyes, and the refractive error that is often seen after laser treatment might be less in anti-VEGF-treated eyes $[20,21]$.

Another pertinent question raised by the BEAT-ROP study is when to end follow-up examinations following anti-VEGF therapy. Like all other intravitreally administered drugs, bevacizumab exits the eye over time via the retinal pigment epithelium and choroidal vasculature leading to decreasing anti-VEGF drug levels in the eye [22]. If the peripheral retina is not yet fully vascularized, there will be a potential source of excessive VEGF that may over time exceed the amount of anti-VEGF drug remaining in the eye leading to reactivation of ROP. Since both the kinetics of VEGF expression in avascular retina and the rate of peripheral vascularization will be different between individuals, there may not be a general rule as to 
how long and how frequently these infants will need to be followed after intravitreal anti-VEGF therapy. A relatively safe situation is reached when there is no (or only very limited) peripheral avascular retina remaining. In cases where full retinal vascularization is not achieved and there are signs of reactivated ROP, however, a sequential approach of first anti-VEGF therapy for central ROP (in zone I or central zone II) followed by laser therapy at a later time point for the remaining peripheral avascular retina with signs of recurring ROP activity may be sensible.

The crucial question of systemic changes in VEGF levels after intravitreal anti-VEGF treatment needs to be addressed and will be discussed in the last section of this review.

\section{ROP Prevention: Insulin-Like Growth Factor Supplementation}

Prevention is better than treatment - perhaps in particular in ROP. Strict monitoring and low target saturations for oxygen supplementation during the early weeks of life reduce the risk of developing severe ROP. However, this must be weighed against an increased mortality risk when oxygen targets are too low [23, 24]. Similar to oxygen targets, other factors have been identified that may prevent the development of ROP when levels are optimized [25]. For example, overall postnatal growth rate is significantly linked to ROP risk [26-33]. A partial explanation of this observation may be better overall health of an infant with good postnatal weight gain, while infants with poor postnatal weight gain are more likely to have other health issues like sepsis or anemia that may indirectly affect ROP development $[34,35]$. However, there are also subnormal levels of growth-related factors that may directly alter the ROP risk. This is the case for the insulin-like growth factor (IGF)-1, a growth factor found to be crucial for normal retinal vascular development [36, 37]. Mice deficient in IGF-1 do not develop normal functional retinal vasculature at the same rate as wild-type controls [37]. This observation is very relevant to the early stages of postnatal retinal development. As stated above, the earlier an infant is born, the more avascular retina is present that needs to be vascularized postnatally in order to prevent the later stages of ROP with preretinal vascular ridge and pathologic vascular proliferation. If a prematurely born infant lacks optimal IGF-1 postnatally, this infant will be less likely to achieve a retinal vascular growth rate during the early weeks of life sufficient to functionally vascularize the retina before ischemia sets in and promotes excessive amounts of pro-angiogenic growth factors leading to proliferative stages of ROP.

Unlike VEGF, IGF-1 is a systemic factor that is mainly produced from the liver, reaching the retina via the systemic circulation $[38,39]$. Lower systemic IGF-1 levels were associated with a higher risk for ROP [40]. Based on these observations, clinical trials are underway to evaluate the effect normalizing systemic IGF-1 levels have on ROP development during the early postnatal phase to match physiologic levels at that developmental stage if the infant were still in utero [40]. The phase I trials found that systemic IGF-1 supplementation is tolerated well by prematurely born infants without observable side effects [40]. Currently, a phase II study is under way to investigate whether IGF-1 supplementation during the first weeks of life is safe and well tolerated (clinical trials identifier NCT01096784).

Ideally, the prevention approach of IGF-1 supplementation would be complemented by anti-VEGF or laser treatment in those infants who fail treatment or miss early intervention. IGF-1 supplementation would be initiated during the first days of life in all infants at high risk of ROP and administered up to a gestational age when intrinsic production of IGF-1 was adequate and when ROP risk was lower. During these first weeks of life (when we never see the proliferative stages of ROP), the retinal vessels would be supplied with the necessary IGF-1 to allow functional vascularization of peripheral retina. Coherent with current screening guidelines, all prematurely born infants would still be screened for ROP from 31 to 32 weeks of PMA onwards. All infants (with or without prior IGF-1 supplementation) developing ROP stages requiring treatment would then be treated using either conventional laser therapy or, in appropriate cases, intravitreal anti-VEGF therapy, dependent on the stage and zone of ROP and taking into account the individual systemic and ophthalmic condition of the infant. Overall, this approach would lead to an individualized treatment regimen in ROP based on normalizing the infant's IGF-1 levels and - from 31 to 32 weeks of PMA and onwards - on the severity and systemic condition of the infant's ROP.

\section{Outlook: Open Questions and Future Developments}

A big question is whether bevacizumab in the currently used half-adult dose is the ideal anti-VEGF regimen $[41,42]$. Lower doses (one quarter or less of the adult dose) may be sufficient to control ROP disease activity [43]. Many commentaries point out the potential risk of 
a sustained ocular and systemic VEGF suppression in a developing infant $[19,44-46]$.

Two facts should be emphasized: first, any anti-VEGF drug administered intravitreally will reach the systemic circulation over time. From adult data, we know that one single intravitreal bevacizumab injection can suppress systemic VEGF levels for weeks [47, 48]. This appears to be also true in infants with ROP [49]. Other anti-VEGF compounds like ranibizumab have shorter systemic halflives. While ranibizumab leaves the eye at a similar rate as bevacizumab, it is cleared much faster from the systemic circulation with a half-life of hours versus days [50]. There has never been a pharmacokinetic study (studying half-life and adequate dose) for anti-VEGF treatment in ROP. The BEAT-ROP study and smaller case series have used the same half-adult dose [51-53] which suppresses ROP activity in most infants. It is not known, however, whether infants might be overtreated. Since ROP usually occurs bilaterally, an infant (often at or below $2 \mathrm{~kg}$ of body weight) will receive the same amount of anti-VEGF drug as a $70-\mathrm{kg}$ adult receiving a unilateral injection for agerelated macular degeneration or diabetic macular edema. Per body weight, the infant's drug exposure is much higher compared to that of the adult. In addition, bevacizumab has - due to its characteristics as a full size antibody - a systemic half-life of several days and can therefore suppress systemic VEGF levels in a developing infant over many weeks [49].

These two questions, whether other anti-VEGF compounds with different pharmacodynamic properties or lower doses might be similarly effective at treating ROP, are currently under investigation in a multicenter randomized double-blind investigator-initiated trial. This study, the CARE-ROP trial, investigates the effects of two different doses of ranibizumab for treatment of ROP (NCT02134457). In addition to improved pharmacodynamics with faster systemic clearance rates for ranibizumab, this drug has been developed explicitly for use in the eye and is approved for intravitreal use in adults for several indications, while bevacizumab is not approved for use in the eye. In two large government-sponsored comparative trials between ranibizumab and bevacizum$\mathrm{ab}$ in adults, comparable ocular efficacy was found for treatment of age-related macular degeneration [54-57]. It is, therefore, likely that ranibizumab will have similar ocular effects as bevacizumab in ROP while reducing the potential risk of systemic side effects by being cleared rapidly from the systemic circulation. In addition, the CARE-ROP study will investigate if a lower dose ( $24 \%$ of the adult dose) is similarly effective at treating ROP as a higher dose ( $40 \%$ of the adult dose). Both doses are lower than the currently used $50 \%$ adult dose of bevacizumab since emerging data indicate that lower doses might be sufficiently effective at controlling pathologic vessel formation in ROP while at the same time potentially allowing better functional vascularization of the peripheral retina with physiologic vessels $[43,58]$. It will be crucial in ROP treatment to find the ideal balance between suppression of aberrant preretinal vessel growth while allowing full physiologic intraretinal vascularization of the retina.

\section{Conclusion}

IGF-1 supplementation and anti-VEGF therapy are two novel medical approaches in treating ROP that have produced promising results in preclinical and clinical studies and have the potential of revolutionizing the way we treat ROP. The two treatment modalities are complementary and might provide an individualized treatment regimen for ROP in the future. IGF-1 supplementation could be a sensible early intervention for preterm infants who have low systemic IGF-1 levels after birth and during the early weeks of life. Normalization of systemic IGF-1 levels to values that are physiologic during in utero development at these ages could thus offer a preventive treatment strategy that may reduce the incidence of ROP. For those infants who develop ROP with pathologic vascular activation, however, initiating IGF-1 supplementation later would not be appropriate. These infants would instead require treatment aimed at reducing aberrant growth of preretinal vessels. This can be achieved by laser photocoagulation, which destroys avascular retinal areas thus eliminating the source of excessive growth factor production. Alternatively, these later stages could be treated with targeted elimination of VEGF, the main vascular growth factor being produced in these avascular retinal areas. Administered in the right dosage and at the right stages, anti-VEGF treatment has the potential of binding and neutralizing excessive angiogenic growth factor levels in the vitreous while at the same time allowing physiologic retinal vascularization to proceed into the peripheral retina, thus saving retinal tissue that would have been otherwise destroyed by laser therapy. For antiVEGF therapy, however, it has to be ensured that local and systemic side effects are kept to a minimum. It is, therefore, of utmost importance to define the ideal substances and dosages for any pharmacological intervention in ROP. 


\section{Acknowledgments}

We are grateful for the support from NEI EY022275, EY017017, P01 HD18655, Lowy Medical Research Foundation (L.E.H.S.), DFG STA1102/5-1 (A.S.) and the European Commission FP7 project 305485 PREVENT-ROP (L.E.H.S. and A.H.).

\section{Disclosure Statement}

L.E.H.S. and A.H. consult for Shire Pharmaceuticals. A.S consults for Novartis.

\section{References}

1 Early Treatment for Retinopathy of Prematurity Cooperative Group: Revised indications for the treatment of retinopathy of prematurity: results of the early treatment for retinopathy of prematurity randomized trial. Arch Ophthalmol 2003;121:1684-1694.

- 2 Hughes S, Yang H, Chan-Ling T: Vascularization of the human fetal retina: roles of vasculogenesis and angiogenesis. Invest Ophthalmol Vis Sci 2000;41:1217-1228.

3 Stahl A, Connor KM, Sapieha P, Chen J, Dennison RJ, Krah NM, Seaward MR, Willett KL, Aderman CM, Guerin KI, Hua J, Löfqvist C, Hellström A, Smith LE: The mouse retina as an angiogenesis model. Invest Ophthalmol Vis Sci 2010;51:2813-2826.

-4 Sonmez K, Drenser KA, Capone A Jr, Trese MT: Vitreous levels of stromal cell-derived factor 1 and vascular endothelial growth factor in patients with retinopathy of prematurity. Ophthalmology 2008;115:1065.e11070.e1.

5 Velez-Montoya R, Clapp C, Rivera JC, Garcia-Aguirre G, Morales-Cantón V, FromowGuerra J, Guerrero-Naranjo JL, Quiroz-Mercado $\mathrm{H}$ : Intraocular and systemic levels of vascular endothelial growth factor in advanced cases of retinopathy of prematurity. Clin Ophthalmol 2010;4:947-953.

-6 Jandeck C, Stahl A: Retinopathy of prematurity (in German). Klin Monbl Augenheilkd 2012;229:559-575; quiz 576-557.

7 Jandeck C, Kellner U, Lorenz B, Seiberth V: Guidelines for ophthalmological screening of premature infants in Germany (in German). Klin Monbl Augenheilkd 2008;225:123-130.

8 Multicenter trial of cryotherapy for retinopathy of prematurity. Three-month outcome. Cryotherapy for Retinopathy of Prematurity Cooperative Group. Arch Ophthalmol 1990; 108:195-204.

$\longrightarrow$ Multicenter trial of cryotherapy for retinopathy of prematurity. One-year outcome structure and function. Cryotherapy for Retinopathy of Prematurity Cooperative Group. Arch Ophthalmol 1990;108:1408-1416.

10 McNamara JA, Tasman W, Brown GC, Federman JL: Laser photocoagulation for stage $3+$ retinopathy of prematurity. Ophthalmology 1991;98:576-580.

-11 Landers MB 3rd, Toth CA, Semple HC, Morse LS: Treatment of retinopathy of prematurity with argon laser photocoagulation. Arch Ophthalmol 1992;110:44-47.
12 Fleming TN, Runge PE, Charles ST: Diode laser photocoagulation for prethreshold, posterior retinopathy of prematurity. Am J Ophthalmol 1992;114:589-592.

13 Simpson JL, Melia M, Yang MB, Buffenn AN, Chiang MF, Lambert SR: Current role of cryotherapy in retinopathy of prematurity: a report by the American Academy of Ophthalmology. Ophthalmology 2012;119:873-877.

14 Choi J, Kim JH, Kim SJ, Yu YS: Long-term results of lens-sparing vitrectomy for progressive posterior-type stage $4 \mathrm{a}$ retinopathy of prematurity. Korean J Ophthalmol 2012;26: 277-284.

15 Repka MX, Tung B, Good WV, Capone A Jr, Shapiro MJ: Outcome of eyes developing retinal detachment during the Early Treatment for Retinopathy of Prematurity Study. Arch Ophthalmol 2011;129:1175-1179.

16 Mintz-Hittner HA, Kennedy KA, Chuang AZ: Efficacy of intravitreal bevacizumab for stage $3+$ retinopathy of prematurity. $\mathrm{N}$ Engl J Med 2011;364:603-615.

$17 \mathrm{Hu}$ J, Blair MP, Shapiro MJ, Lichtenstein SJ, Galasso JM, Kapur R: Reactivation of retinopathy of prematurity after bevacizumab injection. Arch Ophthalmol 2012;130:1000-1006.

18 Lee BJ, Kim JH, Heo H, Yu YS: Delayed onset atypical vitreoretinal traction band formation after an intravitreal injection of bevacizumab in stage 3 retinopathy of prematurity. Eye (Lond) 2012;26:903-909; quiz 910.

19 Hard AL, Hellstrom A: On the use of antiangiogenetic medications for retinopathy of prematurity. Acta Paediatr 2011;100:10631065.

20 Harder BC, Schlichtenbrede FC, von Baltz S, Jendritza W, Jendritza B, Jonas JB: Intravitreal bevacizumab for retinopathy of prematurity: refractive error results. Am J Ophthalmol 2013;155:1119.e1-1124. e1.

-21 Martínez-Castellanos MA, Schwartz S, Hernández-Rojas ML, Kon-Jara VA, GarcíaAguirre G, Guerrero-Naranjo JL, Chan RV, Quiroz-Mercado H: Long-term effect of antiangiogenic therapy for retinopathy of prematurity up to 5 years of follow-up. Retina 2013; 33:329-338.

22 Meyer CH, Krohne TU, Holz FG: Intraocular pharmacokinetics after a single intravitreal injection of $1.5 \mathrm{mg}$ versus $3.0 \mathrm{mg}$ of bevacizumab in humans. Retina 2011;31:1877-1884.

23 Stenson BJ: Oxygen targets for preterm infants. Neonatology 2013;103:341-345.
24 Chen ML, Guo L, Smith LE, Dammann CE, Dammann O: High or low oxygen saturation and severe retinopathy of prematurity: a meta-analysis. Pediatrics 2010;125:e1483-e1492.

25 Raghuveer TS, Bloom BT: A paradigm shift in the prevention of retinopathy of prematurity. Neonatology 2011;100:116-129.

26 Fortes Filho JB, Bonomo PP, Maia M, Procianoy RS: Weight gain measured at 6 weeks after birth as a predictor for severe retinopathy of prematurity: study with 317 very low birth weight preterm babies. Graefes Arch Clin Exp Ophthalmol 2009;247:831-836.

27 Hellström A, Ley D, Hansen-Pupp I, Niklasson A, Smith L, Löfquist C, Hård AL: New insights into the development of retinopathy of prematurity - importance of early weight gain. Acta Paediatr 2010;99:502-508.

28 Löfqvist C, Andersson E, Sigurdsson J, Engström E, Hård AL, Niklasson A, Smith LE, Hellström A: Longitudinal postnatal weight and insulin-like growth factor I measurements in the prediction of retinopathy of prematurity. Arch Ophthalmol 2006;124:1711-1718.

29 Löfqvist C, Hansen-Pupp I, Andersson E, Holm K, Smith LE, Ley D, Hellström A: Validation of a new retinopathy of prematurity screening method monitoring longitudinal postnatal weight and insulinlike growth factor I. Arch Ophthalmol 2009;127:622-627.

30 Stahl A, Chen J, Sapieha P, Seaward MR, Krah NM, Dennison RJ, Favazza T, Bucher F, Löfqvist C, Ong H, Hellström A, Chemtob S, Akula JD, Smith LE: Postnatal weight gain modifies severity and functional outcome of oxygen-induced proliferative retinopathy. Am J Pathol 2010;177:2715-2723.

31 Wallace DK, Kylstra JA, Phillips SJ, Hall JG: Poor postnatal weight gain: a risk factor for severe retinopathy of prematurity. J AAPOS 2000;4:343-347.

32 Wu C, Löfqvist C, Smith LE, Vanderveen DK, Hellström A; WINROP Consortium: Importance of early postnatal weight gain for normal retinal angiogenesis in very preterm infants: a multicenter study analyzing weight velocity deviations for the prediction of retinopathy of prematurity. Arch Ophthalmol 2012;130:992-999.

$33 \mathrm{Wu}$ C, Vanderveen DK, Hellström A, Löfqvist C, Smith LE: Longitudinal postnatal weight measurements for the prediction of retinopathy of prematurity. Arch Ophthalmol 2010; 128:443-447.
IGF-1 and Anti-VEGF in ROP: Has the Time Come?
Neonatology 2014;106:254-260 DOI: $10.1159 / 000365132$ 
34 Tolsma KW, Allred EN, Chen ML, Duker J, Leviton A, Dammann O: Neonatal bacteremia and retinopathy of prematurity: The ELGAN study. Arch Ophthalmol 2011;129: 1555-1563.

35 Weintraub Z, Carmi N, Elouti H, Rumelt S: The association between stage 3 or higher retinopathy of prematurity and other disorders of prematurity. Can J Ophthalmol 2011;46: 419-424.

- 36 Hellström A, Carlsson B, Niklasson A, Segnestam K, Boguszewski M, de Lacerda L, Savage M, Svensson E, Smith L, Weinberger D, Albertsson Wikland K, Laron Z: IGF-I is critical for normal vascularization of the human retina. J Clin Endocrinol Metab 2002;87: 3413-3416.

- 37 Hellstrom A, Perruzzi C, Ju M, Engstrom E, Hard AL, Liu JL, Albertsson-Wikland K, Carlsson B, Niklasson A, Sjodell L, LeRoith D, Senger DR, Smith LE: Low IGF-I suppresses VEGF-survival signaling in retinal endothelial cells: direct correlation with clinical retinopathy of prematurity. Proc Natl Acad Sci USA 2001;98:5804-5808.

- 38 Spranger J, Buhnen J, Jansen V, Krieg M, Meyer-Schwickerath R, Blum WF, Schatz H, Pfeiffer AF: Systemic levels contribute significantly to increased intraocular IGF-I, IGF-II and IGF-BP3 [correction of IFG-BP3] in proliferative diabetic retinopathy. Horm Metab Res 2000;32:196-200.

-39 Engström E, Niklasson A, Wikland KA, Ewald U, Hellström A: The role of maternal factors, postnatal nutrition, weight gain, and gender in regulation of serum IGF-I among preterm infants. Pediatr Res 2005;57:605610.

-40 Hellström A, Engström E, Hård AL, Albertsson-Wikland K, Carlsson B, Niklasson A, Löfquist C, Svensson E, Holm S, Ewald U, Holmström G, Smith LE: Postnatal serum insulin-like growth factor I deficiency is associated with retinopathy of prematurity and other complications of premature birth. Pediatrics 2003;112:1016-1020.
41 Avery RL: Bevacizumab (Avastin) for retinopathy of prematurity: wrong dose, wrong drug, or both? J AAPOS 2012;16:2-4

42 Spandau U: What is the optimal dosage for intravitreal bevacizumab for retinopathy of prematurity? Acta Ophthalmol 2013;91:e154

43 Harder BC, von Baltz S, Jonas JB, Schlichtenbrede FC: Intravitreal low-dosage bevacizumab for retinopathy of prematurity. Acta Ophthalmol 2013, Epub ahead of print.

44 Lim LS, Mitchell P, Wong TY: Bevacizumab for retinopathy of prematurity. N Engl J Med 2011;364:2360; author reply 2361-2362.

45 Gilbert CE, Zin A, Darlow B: Bevacizumab for retinopathy of prematurity. N Engl J Med 2011;364:2359-2360; author reply 23612352.

6 Good WV, Palmer EA: Bevacizumab for retinopathy of prematurity. N Engl J Med 2011; 364:2359; author reply 2361-2352.

47 Zehetner C, Kirchmair R, Huber S, Kralinger MT, Kieselbach GF: Plasma levels of vascular endothelial growth factor before and after intravitreal injection of bevacizumab, ranibizumab and pegaptanib in patients with agerelated macular degeneration, and in patients with diabetic macular oedema. Br J Ophthalmol 2013;97:454-459.

48 Matsuyama K, Ogata N, Matsuoka M, Wada M, Takahashi K, Nishimura T: Plasma levels of vascular endothelial growth factor and pigment epithelium-derived factor before and after intravitreal injection of bevacizumab. $\mathrm{Br}$ Ophthalmol 2010;94:1215-1218.

49 Sato T, Wada K, Arahori H, Kuno N, Imoto K, Iwahashi-Shima C, Kusaka S: Serum concentrations of bevacizumab (Avastin) and vascular endothelial growth factor in infants with retinopathy of prematurity. Am J Ophthalmol 2012;153:327.e1-333.e1

50 Krohne TU, Holz FG, Meyer CH: Pharmacokinetics of intravitreally administered VEGF inhibitors (in German). Ophthalmologe 2014;111:113-120.
51 Dorta P, Kychenthal A: Treatment of type 1 retinopathy of prematurity with intravitreal bevacizumab (Avastin). Retina 2010;30:S24S31.

52 Lalwani GA, Berrocal AM, Murray TG, Buch M, Cardone S, Hess D, Johnson RA, Puliafito CA: Off-label use of intravitreal bevacizumab (Avastin) for salvage treatment in progressive threshold retinopathy of prematurity. Retina 2008;28:S13-S18.

-53 Nazari H, Modarres M, Parvaresh MM Ghasemi Falavarjani K: Intravitreal bevacizumab in combination with laser therapy for the treatment of severe retinopathy of prematurity (ROP) associated with vitreous or retinal hemorrhage. Graefes Arch Clin Exp Ophthalmol 2010;248:1713-1718.

54 Martin DF, Maguire MG, Fine SL, Ying GS, Jaffe GJ, Grunwald JE, Toth C, Redford M, Ferris FL 3rd: Ranibizumab and bevacizumab for treatment of neovascular age-related macular degeneration: two-year results. Ophthalmology 2012;119:1388-1398.

- 55 Martin DF, Maguire MG, Ying GS, Grunwald JE, Fine SL, Jaffe GJ: Ranibizumab and bevacizumab for neovascular age-related macular degeneration. N Engl J Med 2011;364:18971908.

56 Chakravarthy U, Harding SP, Rogers CA, Downes SM, Lotery AJ, Culliford LA, Reeves BC: Alternative treatments to inhibit VEGF in age-related choroidal neovascularisation: 2 -year findings of the IVAN randomised controlled trial. Lancet 2013;382:1258-1267.

57 Chakravarthy U, Harding SP, Rogers CA, Downes SM, Lotery AJ, Wordsworth S, Reeves BC: Ranibizumab versus bevacizumab to treat neovascular age-related macular degeneration: one-year findings from the IVAN randomized trial. Ophthalmology 2012;119: 1399-1411.

58 Lutty GA, McLeod DS, Bhutto I, Wiegand SJ: Effect of VEGF trap on normal retinal vascular development and oxygen-induced retinopathy in the dog. Invest Ophthalmol Vis Sci 2011;52:4039-4047. 